INTERVENTIONAL CARDIOLOGY

\title{
Trimetazidine in the prevention of contrast-induced nephropathy after coronary procedures
}

\author{
Alper O Onbasili, Yavuz Yeniceriglu, Pınar Agaoglu, Aslıhan Karul, Tarkan Tekten, Harun Akar, \\ Guzel Discigil
}

See end of article for authors' affiliations

......................

Correspondence to Associate Professor

Dr A O Onbasili,

Department of Cardiology,

School of Medicine, Adnan

Menderes University, 09100

Aydin, Turkey; aonbasili@

adu.edu.tr

Accepted

19 September 2006

Published Online First

25 October 2006

Objective: To evaluate the efficacy of trimetazidine (TMZ) in the prevention of contrast-induced nephropathy $(\mathrm{CIN})$ in patients with high serum creatinine levels undergoing coronary angiography/angioplasty.

Methods: TMZ (20 mg thrice daily) was administered orally for $72 \mathrm{~h}$ starting $48 \mathrm{~h}$ before the procedure. All patients were given intravenous saline $(0.9 \%$ ) at a rate of $1 \mathrm{ml} / \mathrm{kg}$ of body weight per hour for $24 \mathrm{~h}$ starting $12 \mathrm{~h}$ beforehand. Serum creatinine levels were measured before the procedure, $48 \mathrm{~h}$ and 7 days after the procedure. Increase in serum creatinine level exceeding $0.5 \mathrm{mg} /$ day or one quarter of the basal value is considered as CIN. Venous blood samples for serum total antioxidant capacity (TAC) measurement were drawn before and after coronary angiography.

Results: Basal serum creatinine levels and TAC were similar in TMZ and control groups. Serum creatinine levels in the control group increased significantly 2 days after the procedure, and returned to the baseline values on the seventh day. However, it did not change significantly on the second day, and even significantly decreased on the seventh day in the TMZ group. CIN developed in 2.5\% (1/40) of patients in the TMZ group and in $16.6 \%(7 / 42)$ of patients in the control group $(p<0.05)$. TAC values were not different between treatment groups.

Conclusion: TMZ along with isotonic saline infusion is more effective than isotonic saline alone in reducing the risk of $\mathrm{CIN}$ in patients with pre-existing renal dysfunction.

C ontrast-induced nephropathy (CIN) is a serious complication of coronary angiography that is associated with considerably increased mortality and morbidity, including the need for short-term haemodialysis, extended hospitalisation and permanent impairment of renal function. ${ }^{12}$ CIN after coronary angiography is observed more frequently in patients with chronic renal insufficiency, particularly in patients with diabetes mellitus and/or dehydration and/or congestive heart failure. ${ }^{2-5}$ Larger doses of contrast medium and intravascular injection of contrast agent are also associated with higher incidence of CIN ${ }^{6}$ CIN has been reported to occur in $11-44 \%$ of patients with moderate renal insufficiency. ${ }^{2} 67$ Pre-existing renal dysfunction is the greatest independent predictor of CIN, and its severity directly correlates with the incidence of CIN. ${ }^{3}{ }^{6-10}$

Previous reports suggest that the formation of reactive oxygen radicals, renal medullar ischaemia during reperfusion after contrast-induced vasoconstriction and direct tubular damage secondary to the contrast agent have an important role in the injury mechanisms of CIN. ${ }^{11-14}$ Many types of prophylaxis regimens have been used in an attempt to prevent CIN. But, to date only hydration with isotonic saline is generally accepted in the prevention of CIN. ${ }^{14-18}$

Trimetazidine (TMZ) has been described as a cellular antiischaemic agent. ${ }^{19}$ Previous studies demonstrated that TMZ prevents the deleterious effects of ischaemia-reperfusion at both the cellular and the mitochondrial levels, and exerts potent antioxidant activity on various tissue preparations. ${ }^{2021}$ TMZ inhibits the excessive release of oxygen-free radicals, increases glucose metabolism, limits intracellular acidosis, protects ATP stores, reduces membrane lipid peroxidation and inhibits neutrophil infiltration after ischaemia-reperfusion. ${ }^{22}{ }^{23}$ Data concerning the effects of TMZ are derived mainly from studies related to cardiology, and data available on the renal effects of TMZ are limited..$^{24-27}$
Based on the assumption that reactive oxygen radicals and renal medullar ischaemia might be involved in the pathogenesis of CIN, we hypothesised that use of an agent with antiischaemic and antioxidant properties-namely, TMZ-may be beneficial in prevention of CIN. To test our hypothesis, we conducted a randomised, prospective, controlled trial in patients with chronic renal insufficiency undergoing coronary procedures.

\section{METHODS}

A total of 82 (25 women, 57 men, mean (SD) age 60 (10) years) consecutive patients with a serum creatinine level $\geqslant 1.2 \mathrm{mg} / \mathrm{dl}$ $(\geqslant 106 \mathrm{mmol} / \mathrm{l}$ ) or creatinine clearance of $<50 \mathrm{ml} / \mathrm{min}$ (calculated by the formula of Cockcroft and Gault ${ }^{28}$ ) undergoing coronary procedures were prospectively studied. Patients were randomly assigned to two groups: TMZ $(\mathrm{n}=40)$ and control $(n=42)$. Patients with acute renal failure, acute myocardial infarction requiring primary or rescue coronary intervention, cardiogenic shock, patients already on renal replacement treatments or those with a known allergy to TMZ were excluded from the study. Indications of the coronary interventions were acute coronary syndrome $(n=46)$, stable angina $(\mathrm{n}=23)$, dilated cardiomyopathy $(\mathrm{n}=7)$ and preoperative assessment $(n=6)$. In all, 19 patients had diabetes mellitus (all of them type II). The patients and controls underwent echocardiographic examination (HP Sonos 5500, Andover, Massachusetts, USA). Ejection fraction of the left ventricle was calculated with Teicholtz formula.

The study protocol was approved by the institutional review board, and all patients provided written informed consent.

Abbreviations: ABTS, 2, 2'-azino-bis-3-ethylbenzothiazoline sulphonate; CIN, contrast-induced nephropathy; TAC, total antioxidant capacity; TMZ, trimetazidine 


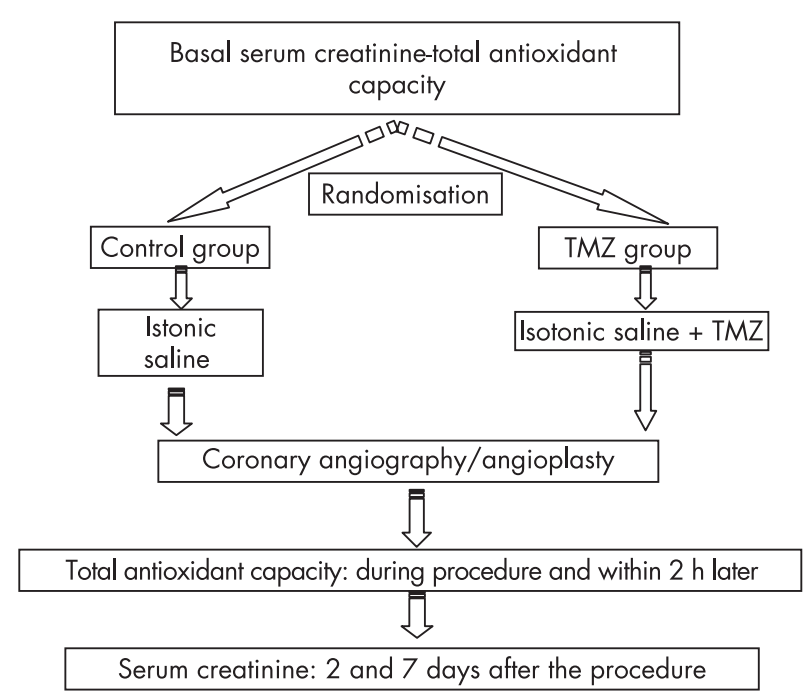

Figure 1 The design of study protocol. TMZ, trimetazidine.

\section{Study protocol}

This study was a prospective double-blind, randomised, controlled trial. Patients with mild renal insufficiency (basal creatinine level between 1.2 and $2.5 \mathrm{mg} / \mathrm{dl}$ ) were enrolled into the study. Patients were randomly allocated into TMZ or control groups. Standard parenteral hydration protocol (isotonic saline at a rate of $1 \mathrm{ml} / \mathrm{kg}$ of body weight per hour starting $12 \mathrm{~h}$ before angiography and up to $12 \mathrm{~h}$ thereafter) was applied to patients in both groups. Additionally, patients in the TMZ group were administered TMZ (20 mg thrice daily orally) for $72 \mathrm{~h}$ starting $48 \mathrm{~h}$ before the procedure. The same contrast agent (iopramide, non-ionic, low osmolality, Ultravist 370/100, Schering, Germany) was used in all procedures at boluses of $8-15 \mathrm{ml}$. The decision to perform PCI, deployment of stents and the use of glycoprotein IIb/IIIa antagonists was left to the discretion of the interventional cardiologist.

Serum creatinine and urea concentrations were measured $48 \mathrm{~h}$ and immediately before coronary angiography, $48 \mathrm{~h}$ and 7 days after the procedure. Serum creatinine concentration immediately before coronary angiography was referred to as the baseline level.

Venous blood samples for serum total antioxidant capacity (TAC) measurement were drawn before TMZ administration, immediately after and within $2 \mathrm{~h}$ following coronary angiography. Venous blood samples were collected from patients and controls. After centrifugation at $3000 \mathrm{rpm}$ for $10 \mathrm{~min}$, serum samples were stored at $-80^{\circ} \mathrm{C}$ until assay time. The TAC evaluation in $\mathrm{mmol} / \mathrm{l}$ was performed in human plasma using a commercially available kit (RANDOX NX 2332 test, Laboratoires Randox, Mauguio, France). The assay is based on the oxidation of a colourless molecule, the reduced 2, 2'azino-bis-(3-ethylbenzothiazoline sulphonate) (ABTS), incubated at $37^{\circ} \mathrm{C}$ with a peroxidase (metmyoglobin) and hydrogen peroxide $\left(\mathrm{H}_{2} \mathrm{O}_{2}\right)$ to produce a relatively stable blue-green chromogen, the radical cation ABTS+. The optical density of this chromogen is measured at a wavelength of $600 \mathrm{~nm}$ using a spectrophotometer (UV 160-A Schimadzu). Plasma antioxidants cause suppression of the production of blue-green colour to a degree that is proportional to their concentration. Briefly, in test tubes containing $20 \mu \mathrm{l}$ of reagent blank, standard (6-hydroxy-2,5,7,8-tetramethylchroman-2-carboxylic acid) or sample, $1 \mathrm{ml}$ of chromogen (metmyoglobin $(610 \mu \mathrm{mol} / \mathrm{l})$ and ABTS $(6.1 \mu \mathrm{mol} / \mathrm{l})$ in phosphate buffer, $5 \mathrm{mmol} / \mathrm{l}, \mathrm{pH}$ 7.4) and $200 \mu \mathrm{l}$ of $\mathrm{H}_{2} \mathrm{O}_{2}(250 \mu \mathrm{mol} / \mathrm{l})$ were added. Then, exactly 3 min
Table 1 Clinical characteristics of the treatment groups

\begin{tabular}{llll}
\hline & TMZ (n=40) & Control (n=42) & $\mathrm{p}$ Value \\
\hline $\begin{array}{l}\text { Age (years) } \\
\text { Men/women }\end{array}$ & $61(10)$ & $60(11)$ & $\mathrm{NS}$ \\
$\begin{array}{l}\text { Blood pressure (mm Hg) } \\
\quad \text { Systolic }\end{array}$ & $25 / 15$ & $32 / 10$ & $\mathrm{NS}$ \\
$\quad$ & $146(28)$ & $149(26)$ & $\mathrm{NS}$ \\
$\quad$ Diastolic & $77(8)$ & $79(9)$ & $\mathrm{NS}$ \\
Diabetes mellitus (\%) & 20 & 26 & $\mathrm{NS}$ \\
BMI & $26.6(4.2)$ & $25.9(2.7)$ & $\mathrm{NS}$ \\
LVEF (\%) & $48(20)$ & $47(18)$ & $\mathrm{NS}$ \\
TAC (mmol/ml) & $2.15(0.14)$ & $2.25(0.14)$ & $\mathrm{NS}$ \\
Baseline serum creatinine & $1.31(0.25)$ & $1.26(0.16)$ & $\mathrm{NS}$ \\
(mg/dl) & & \\
(mmol/l) & $116.4(22.8)$ & $111.9(14.9)$ & $\mathrm{NS}$ \\
Baseline creatinine clearance & $54.4(13)$ & $52.4(11)$ & $\mathrm{NS}$ \\
(ml/min) & & & \\
\hline
\end{tabular}

BMI, body mass index; LVEF, left ventricular ejection fraction; NS, not significant; TAC, total antioxidant capacity; TMZ, trimetazidine.

Values are represented as mean (SD).

after mixing and incubation at $37^{\circ} \mathrm{C}$, the variation of optical density was read at a wavelength of $600 \mathrm{~nm}$, allowing the determination of the total antioxidant status. In kit prospectus, the reference range was $1.37-1.77 \mathrm{mmol} / \mathrm{l}$. Figure 1 shows the study protocol.

The end point of the study was the development of CIN, which was defined as an absolute increase in serum creatinine of $0.5 \mathrm{mg} / \mathrm{dl}$, or a relative increase of $25 \%$ in serum creatinine at 24 or $48 \mathrm{~h}$ after the procedure compared with the baseline.

\section{Statistical analysis}

We projected the sample size from the study of Tepel et al, ${ }^{29}$ which demonstrated the proportion developing an increase in serum creatinine concentration of $\geqslant 0.5 \mathrm{mg} / \mathrm{dl} 48 \mathrm{~h}$ after administration of the contrast agent among the groups. The significance level was set at 0.05 and the power at 0.80 . We calculated that the number of patients required for a TMZ versus placebo study is 40 per group.

All values are given as mean (SD). Clinical and demographic characteristics of the study groups were compared by means of the Student's t test for continuous measures. Categorical variables were presented as percentages and were compared using the $\chi^{2}$ statistics or Fisher exact test. A p value $<0.05$ was considered significant. All statistical tests were two sided. Statistical analysis was performed using SSPS software V.8.0.0.

\section{RESULTS}

Table 1 summarises the clinical and demographic characteristics of the study patients. Baseline indexes of renal function, TAC and baseline characteristics were similar when both groups were compared. Table 2 summarises the characteristics of the angiographic procedures. The vascular access approach was similar in the two treatment groups. The volume of contrast

Table 2 Characteristics of the angiographic procedures

\begin{tabular}{lccl}
\hline & TMZ & Control & p Value \\
\hline Catheterisation approach (\%) & & & \\
$\quad$ Radial artery & 14 & 12 & NS \\
$\quad$ Femoral artery & 86 & 88 & NS \\
Angiography alone (\%) & 25 & 23 & NS \\
Angiography and angioplasty (\%) & 20 & 18 & NS \\
Angiography and angioplasty with & 55 & 59 & NS \\
stent (\%) & & 240 & NS \\
Contrast volume (ml) & 225 & 240 \\
\hline
\end{tabular}

NS, not significant; TMZ, trimetazidine 
Table 3 Serum creatinine and creatinine clearance changes at baseline, 2 and 7 days after cardiac catheterisation in trimetazidine and control groups

\begin{tabular}{|c|c|c|c|c|c|c|}
\hline & Baseline (I) & 2nd day (II) & 7th day (III) & $\begin{array}{l}\text { p Value } \\
\text { (I-II) }\end{array}$ & $\begin{array}{l}\text { p Value } \\
\text { (I-III) }\end{array}$ & $\begin{array}{l}\text { p Value } \\
\text { (III-III) }\end{array}$ \\
\hline \multicolumn{7}{|l|}{ TMZ } \\
\hline $\begin{array}{l}\text { Creatinine }(\mathrm{mg} / \mathrm{dl}) \\
(\mathrm{mmol} / \mathrm{l})\end{array}$ & $\begin{array}{l}1.31(0.25) \\
116.4(22.8)\end{array}$ & $\begin{array}{l}1.31(0.29) \\
115.8(2.3)\end{array}$ & $\begin{array}{l}1.25(0.27) \\
1109(24.4)\end{array}$ & NS & $<0.05$ & $<0.05$ \\
\hline $\begin{array}{l}\text { Creatinine clearance } \\
\text { Control }\end{array}$ & $\begin{array}{l}116.4(12.8) \\
54.4(13)\end{array}$ & $53.2(13.6)$ & $\begin{array}{l}110.9(12.4) \\
58.9(12.1)\end{array}$ & NS & $<0.05$ & $<0.05$ \\
\hline $\begin{array}{l}\text { Creatinine (mgr/dl) } \\
\text { (mmol/l) }\end{array}$ & $\begin{array}{l}1.26(0.16) \\
111.9(14.9)\end{array}$ & $\begin{array}{l}1.42(0.43) \\
125.6(38.5)\end{array}$ & $\begin{array}{l}1.30(0.41) \\
115.7(36.9)\end{array}$ & $<0.05$ & NS & $<0.05$ \\
\hline Creatinine clearance & $52.4(10.8)$ & $46.5(10.5)$ & $52.0(10.7)$ & $<0.05$ & NS & $<0.05$ \\
\hline
\end{tabular}

medium used was not significantly different between the treatment groups.

CIN occurred in $2.5 \%(1 / 40)$ of patients in the TMZ group and in $16.6 \%(7 / 42)$ of patients in the control group $(p<0.05)$. Although baseline serum creatinine levels did not differ significantly, serum creatinine levels on the second and seventh days after the procedure were higher in the control group than in the TMZ group (table 3). Baseline serum creatinine significantly increased on the second day and returned to baseline values with a significant decrement on the seventh day after catheterisation in the control group (table 3). However, in the TMZ group, serum creatinine value did not present any increment on the second day and even decreased significantly on the seventh day after the procedure (table 3). Baseline creatinine clearance decreased significantly on the second day and returned to baseline values on the seventh day after catheterisation in the control group (table 3). However, in the TMZ group, creatinine clearance decreased insignificantly on day 2 and increased significantly on day 7 (table 3 ).

TAC values measured before TMZ administration, just after and within $2 \mathrm{~h}$ after catheterisation were not different between treatment groups (table 4). Serum TAC was decreased insignificantly after administration of contrast medium, and returned to baseline values after $2 \mathrm{~h}$ in both TMZ and control groups (fig 2).

Changes in serum creatinine levels were not significantly different in patients with diabetes compared with patients without diabetes. CIN occurred in 1 of $10(10 \%)$ TMZ-treated patients with diabetes and in 1 of $9(11.1 \%)$ control patients with diabetes $(\mathrm{p}>0.05)$.

No complication and potential side effects related to TMZ administration were observed. Pulmonary oedema occurred in 2 of 82 patients. Two patients with pulmonary oedema were treated with intravenous furosemid administration. Other patients did not receive furosemid. In all, 19 patients (11 patients in the TMZ group, 8 patients in the control group) were using tiazides for hypertension treatment. In one patient, left

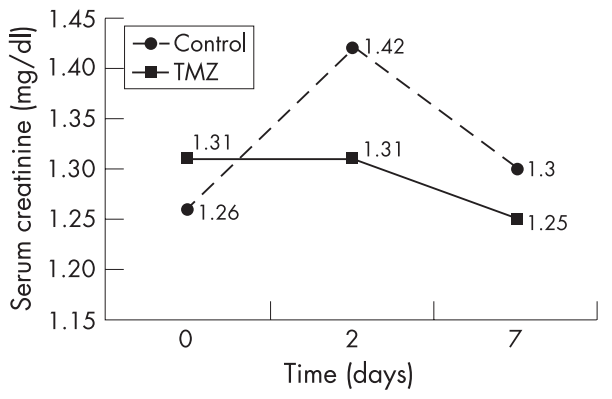

Figure 2 Serum creatine levels in control and trimetazidine (TMZ) groups. ventricular failure occurred before angiography and the procedure was postponed. In the other patient, this complication occurred after angiography. None of the patients who developed CIN required dialysis.

\section{DISCUSSION}

The major finding of our study is the observation of a significant decrease in the incidence of CIN by means of TMZ administration in conjunction with saline when compared with saline alone in patients undergoing coronary procedures.

Prospective studies have produced extremely varied estimates of the incidence of CIN. The reported incidence of CIN ranges from none to $>50 \% .^{30}{ }^{31}$ These discrepancies are due to differences in patient co-morbidity and the presence of other potential causes of acute renal failure. Two epidemiological studies reported rates of $14.4 \%$ and $11.1 \%$, respectively, in two series of 1826 and 1196 patients undergoing invasive cardiac procedures. ${ }^{2} 6$ Two larger studies, which included 7586 and 8628 patients who underwent percutaneous coronary intervention, reported CIN incidence of $3.3 \%$ and $16.5 \%$, respectively. ${ }^{8}{ }^{9}$ Our study results are compatible with the literature.

The mechanism of contrast nephrotoxicity is multifactorial. Contrast media has been shown to reduce antioxidant enzyme activity in the rat kidney, and direct cytotoxicity mediated by oxygen-free radicals has been demonstrated in canine and rat models of CIN. ${ }^{32}{ }^{33}$ These animal models have shown that hypertonic contrast media gives rise to production of oxygenfree radicals and leads to apoptosis in renal tubular and glomerular cells. In our study, although non-significant, TAC was decreased with contrast agent administration and increased to baseline value $2 \mathrm{~h}$ later in both TMZ and control groups. Experimental models demonstrate a biphasic response of renal blood flow in response to contrast media, characterised by initial increase and subsequent prolonged decrease in blood flow and glomerular filtration. ${ }^{31-34}$ In addition, shunting from the renal medulla (a region with low oxygen supply and high metabolic demand under normal conditions) to the renal cortex can produce medullary ischaemia and necrosis. ${ }^{35} 36$

TMZ is an anti-ischaemic agent known to improve exercise tolerance and cardiac function in patients with ischaemic heart disease. ${ }^{37}$ It has been shown that pre-treatment with TMZ is effective in reducing the size of the infarct that develops in the blood-perfused rabbit model of myocardial ischaemia. ${ }^{38}$ Various experimental studies have shown that TMZ preserves the intracellular concentration of ATP and inhibits the extracellular leakage of potassium during cellular ischaemia. The potent antioxidant effect of TMZ has been demonstrated in myocardial, renal and hepatic ischaemia-reperfusion injury. ${ }^{39-41}$

Although data about TMZ are mainly derived from its cardiac effects, recent data suggest that TMZ may also be beneficial in attenuation of glycerol, cyclosporine, tacrolimus and ferric 
Table 4 Serum total antioxidant capacity changes at baseline, immediately and $2 \mathrm{~h}$ after cardiac catheterisation

\begin{tabular}{|c|c|c|c|c|c|c|}
\hline Groups & $\begin{array}{l}\text { Before } \\
\text { TMZ (I) }\end{array}$ & $\begin{array}{l}\text { Just after } \\
\text { catheterisation (II) }\end{array}$ & $\begin{array}{l}2 \mathrm{~h} \text { after } \\
\text { catheterisation (III) }\end{array}$ & $\begin{array}{l}\text { p Value } \\
\text { (I-II) }\end{array}$ & $\begin{array}{l}\text { p Value } \\
\text { (I-III) }\end{array}$ & $\begin{array}{l}\text { p Value } \\
\text { (II-III) }\end{array}$ \\
\hline TMZ & $2.27(0.6)$ & $1.91(0.6)$ & $2.22(0.6)$ & NS & NS & NS \\
\hline Control & $2.25(0.7)$ & $1.91(0.7)$ & $2.15(0.7)$ & NS & NS & NS \\
\hline p Value & NS & NS & NS & & & \\
\hline
\end{tabular}

NS, not significant; $T M Z$, trimetazidine

Values are represernted as mean (SD).

nitrillotriacetate-induced renal damage. It may also decrease the damage due to ischaemia-reperfusion injury in renal tissue. Addition of TMZ to organ preservation solutions may improve renal function after transplantation. ${ }^{24-27}$

Identification of renoprotective agents that can prevent CIN has been proven to be difficult. Dopamine, furosemide, mannitol, aminophiline, atrial natriuretic peptide, captopril, calcium canal blockers and alprostadil are not effective in reducing the risk of $\mathrm{CIN}^{1{ }^{11842}}$ Current prospective studies evaluating the role of acetylcysteine in patients undergoing coronary angiography have yielded inconsistent data. ${ }^{43-50}$ Antioxidant acetylcysteine has been suggested to attenuate CIN through scavenging oxygen-free radicals generated as a result of renal tubular toxic damage. ${ }^{51}$ A small clinical study by Marenzi et $a l^{52}$ showed periprocedural haemofiltration to be effective in preventing the deterioration of renal function due to contrast agent. However, two other studies showed no reduction in the rate of CIN. ${ }^{53} 54$ A previous study showed that hydration with sodium bicarbonate before contrast exposure is more effective than hydration with sodium chloride for prophylaxis of contrast-induced renal failure..$^{55}$ Only hydration with saline or half-normal saline has consistently been shown to be more effective than control in reducing the risk of CIN..$^{15-17}$ This study is the first, to the best of our knowledge, to have tested TMZ and found it to be effective in the attenuation of CIN (2.5\% vs $16.6 \%)$ in patients with chronic renal insufficiency who received intravenous contrast agent at cardiac catheterisation.

In our study, we observed no significant change in serum TAC values when inter-group or intra-group analysis was performed. On the other hand, we cannot rule out an antioxidant mechanism since we do not know what is happening at the tissue level. The benefits of TMZ may be associated with its renal cellular anti-ischaemic effect.

Several limitations should be noted. Our study includes a relatively small sample size. Although the relatively small sample size calls for caution in interpreting the study results, this sample size was predetermined from a power calculation based on the findings of Tepel et al. ${ }^{29}$ The dose of oral TMZ chosen for this study was derived from the standard regimen for the treatment of myocardial ischaemia. Relatively low-risk patients with mild renal insufficiency were included in our study. The effect of TMZ on high-risk patients should be investigated in larger prospective clinical studies.

\section{CONCLUSION}

Administration of TMZ (20 mg thrice daily, orally) in conjunction with saline is an effective means of preventing transient renal dysfunction due to radiocontrast agent.

\section{Authors' affiliations \\ Alper O Onbasili, Pınar Agaoglu, Tarkan Tekten, Department of Cardiology, School of Medicine, Adnan Menderes University, Aydin, Turkey \\ Yavuz Yeniceriglu, Harun Akar, Department of Nephrology, School of}

Medicine, Adnan Menderes University, Aydin, Turkey

Aslihan Karul, Department of Biochemistry, School of Medicine, Adnan Menderes University, Aydin, Turkey

Guzel Discigil, Department of Family Medicine, School of Medicine, Adnan Menderes University, Aydin, Turkey

Competing interests: None declared.

\section{REFERENCES}

1 Murphy SW, Barrent BJ, Parfrey PS. Contrast nephropathy. J Am Soc Nephrol 2000;1 1:177-82.

2 McCullough PA, Wolyn R, Rocher LL, et al. Acute renal failure after coronary intervention: incidence, risk factors, and relationship to mortality. Am J Med 1997; 103:368-75.

3 Gruberg I, Mintz GS, Mehran R, et al. The prognostic implications of further renal function deterioration within 48 hours of interventional coronary procedures in patients with pre-existent chronic renal insufficiency. J Am Coll Cardiol 2000;36:1542-8

4 Tomasso C. Contrast induced nephrotoxicity in patients undergoing cardiac catheterization. Cathet Cardiovasc Diagn 1994;31:316-21.

5 Parfrey PS, Griffiths SM, Barrett BJ, et al. Contrast material-induced renal failure in patients with diabetes mellitus, renal insufficiency, or both. A prospective controlled study. N Engl J Med 1989;320:143-9.

6 Rudnick MR, Goldfarb S, Wexler L, et al. Nephrotoxicity of ionic and nonionic contrast media in 1196 patients: a randomized trial. The lohexol Cooperative Study. Kidney Int 1995:47:254-61.

7 Oldemeyer JB, Biddle WP, Wurdeman RL, et al. Acetylcysteine in the prevention of contrast-induced nephropathy after coronary angiography. Am Heart J 2003; 146:E23.

8 Rihal CS, Textor SC, Grill DE, et al. Incidence and prognostic importance of acute renal failure after percutaneous coronary intervention. Circulation 2002;105:2259-64.

9 lakovou I, Dangas G, Mehran R, et al. Impact of gender on the incidence and outcome of contrast-induced nephropathy after percutaneous coronary intervention. J Invasive Cardiol 2003;15:18-22.

10 Schwab SJ, Hlatky MA, Pieper KS, et al. Contrast nephrotoxicity: a randomized controlled trial of a nonionic and an ionic radiographic contrast agent. N Engl J Med 1989;320:149-53.

11 Baliga R, Udea N, Walker PD, et al. Oxidant mechanisms in toxic acute renal failure. Am J Kidney Dis 1997;29:465-77.

12 Bakris GL, Lass N, Gaber AO, et al. Radiocontrast medium-induced declines in renal function: a role for oxygen free radicals. Am J Physiol 1990;258:115-20.

13 Yoshioka T, Fogo A, Beckman JK. Reduced activity of antioxidant enzymes underlies contrast-induced renal injury in volume depletion. Kidney Int 1992;41:1008-15

14 Gami AS, Garovic VD. Contrast nephropathy after coronary angiography. Mayo Clin Proc 2004;79:211-19.

15 Solomon R, Werner C, Mann D, et al. Effects of saline, mannitol, and furosemide to prevent acute decreases in renal function induced by radiocontrast agents. N Engl J Med 1994;331:1416-20.

16 Stevens MA, McCullough PA, Tobin KJ, et al. A prospective randomized trial of prevention measures in patients at high risk for contrast nephropathy: results of the P.R.I.N.C.E. Study. Prevention of Radiocontrast Induced Nephropathy Clinical Evaluation. J Am Coll Cardiol 1999;33:403-11.

17 Abizaid AS, Clark CE, Mintz GS, et al. Effects of dopamine and aminophylline on contrast-induced acute renal failure after coronary angioplasty in patients with preexisting renal insufficiency. Am J Cardiol 1999;83:260-3, A5.

18 Mueller C, Buerkle G, Buettner HJ, et al. Prevention of contrast media-associated nephropathy: randomized comparison of 2 hydration regimens in 1620 patients undergoing coronary angioplasty. Arch Intern Med 2002;162:329-36.

19 Harpey C, Clauser P, Labrid C, et al. Trimetazidine, a cellular antiischemic agent. Cardiovasc Drug Rev 1989;6:292-312.

20 Elimadi A, Settaf A, Morin D, et al. Trimetazidine counteracts the hepatic injury associated with ischemia-reperfusion by preserving mitochondrial function. $J$ Pharmacol Exp Ther 1998;286:23-8.

21 Aubert A, Bernard C, Clauser P, et al. Effect of pnenazine methosulfate on electrophysiological activity of the semisircular canal: antioxidant properties of trimetazidine. Eur J Pharmacol 1989;174:215-25

22 Kantor PF, Lucien A, Kozak R, et al. The antianginal drug trimetazidine shifts cardiac energy metabolism from fatty acid oxidation to glucose oxidation by 
inhibiting mitochondrial long-chain 3-ketoacyl coenzyme A thiolase. Circ Res 2000:86:580-8.

23 Lavanchy N, Martin J, Rossi A. Anti-ischemic effects of trimetazidine: 31P-NMR spectroscopy in the isolated rat heart. Arch Int Pharmacodyn Ther 1987; 286:97-110.

24 Singh D, Chopra K. Effect of trimetazidine on renal ischemia/reperfusion injury in rats. Pharmacol Res 2004;50:623-9.

25 Zoppo A, Faggiotto A, Redaelli L, et al. Trimetazidine counteracts tacrolimus nephrotoxicity in a hypertensive liver transplant patient. Transplantation 1999;68:1211.

26 Havet $\mathrm{T}$, Baumert $\mathrm{H}$, Amor $\mathrm{B}$, et al. Pharmacological limitation of damage to renal medulla after cold storage and transplantation by trimetazidine. $J$ Pharmacol Exp Ther 2000;292:254-60.

27 Singh D, Chander V, Chopra K. Carvedilol and trimetazidine attenuates ferric nitrilotriacetate induced oxidative renal injury in rats. Toxicology 2003:191:143-51.

28 Cockcroft DW, Gault MH. Prediction of creatinin clearance from serum creatinin. Nephron 1976;16:31-41.

29 Tepel M, Van Der Giet M, Schwarzfeld C, et al. Prevention of radiocontrast agent induced conductions in renal function by acetylcysteine. $N$ Engl J Med 2000:343:180-4.

30 Davidson CJ, Hlatky M, Morris KG, et al. Cardiovascular and renal toxicity of nonionic radiographic contrast agent after cardiac catheterization. A prospective trial. Ann Intern Med 1989;110:119-24.

31 Kumar S, Hull JD, Lathi S, et al. Low incidence of renal failure after angiography. Arch Intern Med 1981;141:1268-70.

32 Hizoh I, Haller C. Radiocontrast-induced renal tubular cell apoptosis: hypertonic versus oxidative stress. Invest Radiol 2002;37:428-34.

33 Katholi RE, Woods WT Jr, Taylor GJ, et al. Oxygen free radicals and contras nephropathy. Am J Kidney Dis 1998;32:64-71.

34 Idee JM, Lancelot E, Berthommier C, et al. Effects of non-ionic monomeric and dimeric iodinated contrast media on renal and systemic haemodynamics in rats. Fundam Clin Pharmacol 2000;14:11-18.

35 Heyman SN, Rosenberger C, Rosen S. Regional alterations in rena haemodynamics and oxygenation: a role in contrast medium-induced nephropathy. Nephrol Dial Transplant 2005;20(Suppl 1):i6-11.

36 Liss P, Nygren A, Erikson U, et al. Injection of low and iso-osmolar contrast medium decreases oxygen tension in the renal medulla. Kidney Int 1998:53:698-702.

37 Brottier L, Barat JL, Combe C, et al. Therapeutic value of a cardioprotective agent in patients with severe ischaemic cardiomyopathy. Eur Heart J 1990;1 1:7-12.

38 Noble MIM, Belchr PR, Drake-Holland AJ. Limitation of infarct size by trimetazidine in the rabbit. Am J Cardiol 1995;76:41-4.

39 Grekas D, Dioudis C, Papageorgiou G, et al. Lipid peroxidation after acute renal ischemia and reperfusion in rats: the effect of trimetazidine. Ren Fail 1996;18:545-52.
40 Özden A, Aybek Z, Saydam N, et al. Cytoprotective effect of trimetazidine on $75 \mathrm{~min}$ warm renal ischemia-reperfusion injury in rats. Eur Surg Res 1998;30:227-34.

41 Tsimoyiannis EC, Moutesidou KJ, Moschos CM, et al. Trimetazidine for prevention of hepatic injury induced by ischemia and reperfusion in rats. Eur J Surg 1993;159:89-93.

42 Bailey SR. Past and present attempts to prevent radiocontrast nephropathy. Rev Cardiovasc Med 2001;2:s14-18.

43 Boccalandro F, Amhad M, Smalling RW, et al. Oral acetylcysteine does not protect renal function from moderate to high doses of intravenous radiographic contrast. Catheter Cardiovasc Interv 2003;58:336-41.

44 Allaqaband S, Tumuluri R, Malik AM, et al. Prospective randomized study of Nacetylcysteine, fenoldopam, and saline for prevention of radiocontrast-induced nephropathy. Catheter Cardiovasc Interv 2002;57:279-83.

45 Baker CS, Wragg A, Kumar S, et al. A rapid protocol for the prevention of contrast-induced renal dysfunction: the RAPPID study. J Am Coll Cardiol 2003:41:2114-18.

46 Briguori C, Manganelli F, Scarpato P, et al. Acetylcysteine and contrast agentassociated nephrotoxicity. J Am Coll Cardiol 2002;40:298-303.

47 Diaz-Sandoval L, Kosowsky BD, Losordo DW. Acetylcysteine to prevent angiography-related renal tissue injury (the APART trial). Am J Cardiol 2002;89:356-8.

48 Kay J, Chow WH, Chan TM, et al. Acetylcysteine for prevention of acute deterioration of renal function following elective coronary angiography and intervention: a randomized controlled trial. JAMA 2003;289:553-8.

49 Shyu KG, Cheng JJ, Kuan P. Acetylcysteine protects against acute renal damage in patients with abnormal renal function undergoing a coronary procedure. J Am Coll Cardiol 2002;40:1383-8.

50 Yeniceroglu Y, Yilmaz O, Sarioglu S, et al. Effects of N-acetyl cystein on radiocontrast nephropathy in rats. Scand J Urol Nephrol 2006:40:63-9.

51 Safirstein R, Andrade L, Vieria JM. Acetylcysteine and nephrotoxic effects of radiographic contrast agents: a new use for an old drug. N Engl J Med 2000;343:210-11.

52 Marenzi G, Marana I, Lauri G, et al. The prevention of radiocontrast-agent nephropathy by hemofiltration. N Engl J Med 2003;349:1333-40.

53 Sterner G, Frennby B, Kurkus J, et al. Does post-angiographic hemodialysis reduce the risk of contrast-medium nephropathy. Scand J Urol Nephrol 2000;34:323-6.

54 Lehnert T, Keller E, Gondolf K, et al. Effect of haemodialysis after contrast medium administration in patients with renal insufficiency. Nephrol Dial Transplant 1998;13:358-62.

55 Merten GJ, Burgess WP, Gray LV, et al. Prevention of contrast-induced nephropathy with sodium bicarbonate: a randomized controlled trial. JAMA 2004;291:2328-34.

\section{Access a vast information database with Toll-Free linking}

"Toll-free" linking gives you immediate access to the full text of many of the cited articles in a paper's reference list-FOR FREE. With the support of HighWire's vast journal catalogue, a huge reference library is now open to you. If HighWire hosts the journal, you can view the full text of the referenced article, completely free of charge by following the Free Full Text links in the references. 